\title{
Prediction of Water Content of Eucalyptus Leaves Using 2.4 GHz Radio Wave
}

\author{
Sonam Peden ${ }^{1,2 *}$, Ronald C. Bradbury' ${ }^{1}$ David William Lamb ${ }^{1,3}$, Mark Hedley ${ }^{4}$ \\ ${ }^{1}$ Precision Agriculture Research Group, University of New England, Armidale, NSW, Australia \\ ${ }^{2}$ College of Science and Technology, Royal University of Bhutan, Rinchending, Bhutan \\ ${ }^{3}$ Food Agility Cooperative Research Centre, University of New England, Armidale, NSW, Australia \\ ${ }^{4}$ CSIRO Data61, Marsfield, NSW, Australia \\ Email: *speden@myune.edu.au
}

How to cite this paper: Peden, S., Bradbury, R.C., Lamb, D.W. and Hedley, M. (2021) Prediction of Water Content of Eucalyptus Leaves Using $2.4 \mathrm{GHz}$ Radio Wave. Journal of Electromagnetic Analysis and Applications, 13, 111-122.

https://doi.org/10.4236/jemaa.2021.138008

Received: July 27, 2021

Accepted: August 27, 2021

Published: August 30, 2021

Copyright (c) 2021 by author(s) and Scientific Research Publishing Inc. This work is licensed under the Creative Commons Attribution International License (CC BY 4.0).

http://creativecommons.org/licenses/by/4.0/

\begin{abstract}
Assessing plant water status is important for monitoring plant physiology. Previous studies showed that radio waves are attenuated when passing through vegetation such as trees. The degree of radio frequency (RF) loss has previously been measured for various tree types but the relationship between water content and RF loss has not been quantified. In this study, the amount of water inside leaves was expressed as an effective water path (EWP), the thickness of a hypothetical sheet of $100 \%$ water with the same mass. A $2.4331 \mathrm{GHz}$ radio wave was transmitted through a wooden frame covered on both sides with 5 mm clear acrylic sheets and filled with Eucalyptus laevopinea leaves. The RF loss through the leaves was measured for different stages of drying. The results showed that there is a nonlinear relationship between effective water path (EWP) in $\mathrm{mm}$ and RF loss in $\mathrm{dB}$. It can be concluded that $2.4 \mathrm{GHz}$ frequency radio waves can be used to predict the water content inside eucalyptus leaves $(0<$ EWP $<14 \mathrm{~mm}$; RMSE $\pm 0.87 \mathrm{~mm})$ and demonstrates the potential to measure the water content of whole trees.
\end{abstract}

\section{Keywords}

Radio Attenuation, Leaves, Water Content, Path Loss, Vegetation Depth

\section{Introduction}

Forests, which today cover 30 percent of the world's land surface, are being rapidly and directly transformed in many areas by the impacts of expanding human populations and economies. Less evident are the pervasive effects of ongoing climatic changes on the condition and status of forests around the world. 
Recent examples of drought and heat-related forest stress and dieback are being documented from all forested continents [1].

Eucalypts are iconic Australian forest trees. The Eucalyptus forest type is by far the most common forest type in Australia covering 101 million hectares, which is $77 \%$ of Australia's total native forest area [2]. The prolonged drought experienced in southern Australia between 1996 and 2010 (the Millennium Drought) caused widespread mortality and secondary insect attack in both eucalypt native forests and pine plantations [3]. Species composition has also changed in response to prolonged lower rainfall [4]. Since the mid-1990s, mainland southeast Australia has experienced an 11 percent reduction in April-October rainfall. Drought makes vegetation more flammable, and therefore more likely to support extreme bushfire behaviour [1].

Water stress affects plant growth and development due to reduction in photosynthetic activities [5] [6] [7] and hence affects forest productivity [8] [9]. Canopy leaf wilting is considered an important visible symptom of drought, when water loss by transpiration is greater than absorption by the roots [10] [11]. The detection of plant water status is important for monitoring the physiological status of plants, and the assessment of drought and fire risk in natural plant communities, and the irrigation scheduling of crops [12] [13]. Although field sampling of single leaves and shoots provides the most accurate assessment of plant water status, such methods are not feasible when estimates are required for large areas of vegetation [14].

Previous studies on understanding the interaction between radio waves and vegetation generally have been directed towards the engineering of reliable radio communication networks in that environment. Both empirical [15] [16] [17] [18] [19] and analytical models [20] were developed for radio frequency (RF) loss through vegetation, but these models do not consider the amount of water inside the vegetation. Radio transmission within wireless sensor networks could serve a dual purpose. Quite apart from sending data between sensors in the network, the radio signals themselves could be sensing the medium in the signal path.

For a lossless medium between the transmitter and the receiver, the maximum signal is received via a direct wave. When there is no obstruction between transmitter and receiver, a free-space model is used to estimate the decline in signal strength with the distance that arises from the radio wave spreading out, the so-called free-space loss. This simple model does not consider the influences of the earth surfaces nor considers the effect of obstacles such as trees, vegetation, buildings, uneven walls, lamp posts between the transmitter and the receiver [21]. Radio waves propagating through any type of material may experience further attenuation (also called excess loss) because of reflection, refraction, diffraction, absorption and scattering.

Signal attenuation occurs as the signal wave passes through a single tree, a group of trees or a forest due to absorption and scattering by the discrete ele- 
ments such as the branches, twigs and leaves [15] [22] [23]. Apart from the signal attenuation, fading (variation in signal strength with time) is another issue caused by multiple path propagation due to vegetation as an obstruction. This results from constructive or destructive interference depending on the relative phase of the signals arriving at the receiver. There are other factors such as operating frequency, the distance between the transmitter and receiver and their position relative to vegetation, antenna height, polarization, temperature, humidity, terrain and weather, which can affect the signal transmission.

A canopy of a tree or trees in a path of radio signal path provides stronger attenuation compared to trunks [24] [25] [26]. The attenuation can change substantially due to growth and development stages including leaf loss, fruit growth, etc. [15] [19] [27] [28] [29]. In most forest environments, the fruit size will be much smaller compared to the leaf size and the effect of the fruit on radio propagation might be negligible compared to leaves. But the fruit size might have an additional effect in the agricultural environment, where the canopy density increases with fruit growth. Previous studies on radio propagation through vegetation have revealed that attenuation at any frequency is greater for trees in-leaf compared to trees without leaf [16] [18] [19] [30] [31] [32] [33] [34]. This suggests that leaves are the strongest contribution to attenuation.

If the size of the foliated obstruction through trees and the wavelength of the propagating wave are similar then signal attenuation is observed to be higher [35] because of diffraction and scattering caused by the tree along the propagation path [36].

Le Vine and Karam [37] calculated the attenuation associated with a vegetation canopy using a "discrete scatterer" model, where the vegetation canopy is presented by a sparse layer of discrete, randomly oriented particles such as leaves, stalks, branches, etc. over a homogeneous ground plane (soil). They found that, for frequencies up to $5 \mathrm{GHz}$, the attenuation varies almost linearly with plant water content over the range 0.2 to 0.5 (by volume). But for optical frequencies, the attenuation is relatively independent of both water content and frequency. Nakajima, Ohyama, Juzoji and Ta [38] measured the RF attenuation of individual leaves at 5, 10 and $20 \mathrm{GHz}$ in a waveguide. They also imaged a live tree by measuring $\mathrm{RF}$ attenuation at $10.5 \mathrm{GHz}$ concluding that microwave attenuation by tree foliage should have a strong link to water content in the leaves. The dependency of attenuation on water content is through the dielectric constant which is highly dependent on the water content inside the material. Furthermore, moisture on the surface of leaves of the trees absorbed the signals and caused more attenuation [32] [39] [40] [41].

Radio waves interact strongly with water and eucalyptus leaves are no exception. Rather than treat the attenuation of radio waves by a water-laden eucalyptus canopy as something that must be accounted for and mitigated, the goal of this study is to investigate the feasibility of using the attenuation of radio waves to predict the water content of the eucalypt leaves themselves. In order to test the 
hypothesis that radio wave attenuation can be used to estimate water content of vegetation, this initial investigation examines a simplified system involving a controlled presentation of moisture-laden eucalyptus leaves to propagating radio waves.

We postulate two simplifying assumptions: 1) RF loss relates directly to the total amount of water in the signal path rather than its distribution or density; 2) The leaf material is homogeneous on a wavelength scale. Consequently, we propose that, with regard to its effect on RF loss, the amount of water can be expressed as an effective water path (EWP), equivalent to the thickness of a sheet of $100 \%$ water with the same mass.

\section{Method}

\subsection{Experiment Site and Equipment Used}

All the experiments were carried out at The University of New England main campus located in Armidale, New South Wales, Australia (latitude $30.4867^{\circ} \mathrm{S}$ and longitude $151.6430^{\circ} \mathrm{E}$ ). Two flat-panel, phased-array directional antennas (ARC Wireless Solutions, USA, PA2419B01, $39.1 \mathrm{~cm} \times 39.1 \mathrm{~cm} \times 4.3 \mathrm{~cm}$ ) were used, one as a transmitter connected to a transceiver Beacon (Dosec Design, Australia, EnviroNode Beacon) and the other as a receiver connected to a transceiver hub (Dosec Design, Australia, EnviroNode Hub) operated at $2.4331 \mathrm{GHz}$ frequency. The antenna had a gain of $19 \mathrm{dBi}$, front-to-back ratio of $>30 \mathrm{~dB}$ and $3 \mathrm{~dB}$ beamwidth of $\pm 9^{\circ}$. The antennas were placed outside, facing each other at 6.10 metres apart. A constant transmitted power of 100 milliwatts was used. The hub measured and logged the RSSI (received signal strength indicator, $\mathrm{dBm}$ ) to a removable SD card at 1 minute intervals. The experimental set-up is shown in Figure 1.

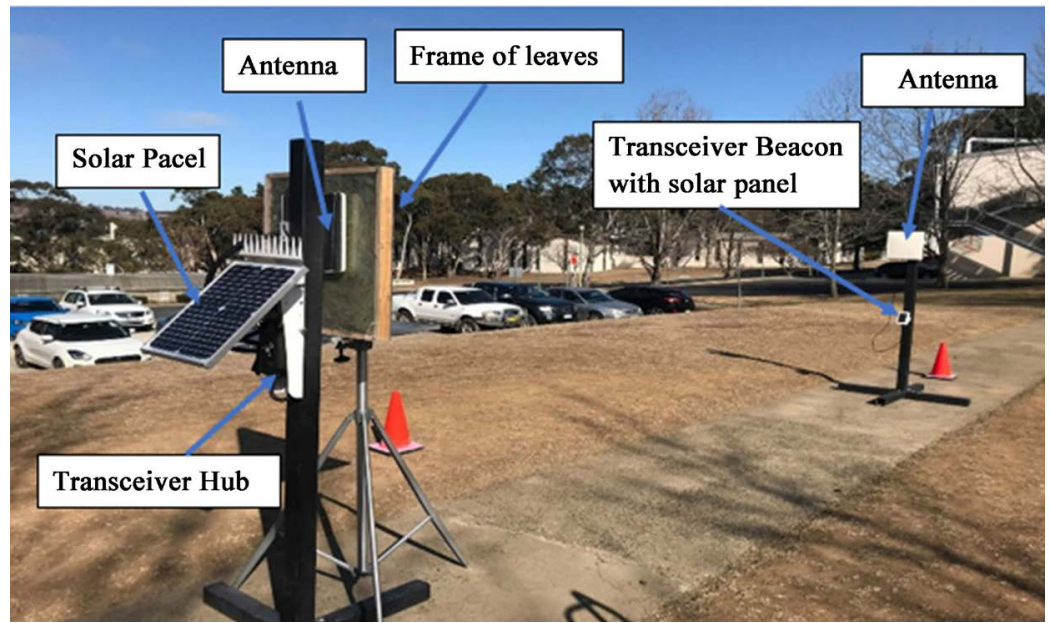

Figure 1. Experimental set-up. Two flat-panel antennas were mounted facing each other $6.10 \mathrm{~m}$ apart. Frame contains the leaves being tested, that was mounted on a tripod immediately in front of one antenna. Solar panels for electrical power are also visible. The RSSI $(\mathrm{dBm})$ was recorded to a removable SD card inside the transceiver Hub every minute. 


\subsection{Verifying the Experimental Set Up}

Some preliminary measurements were made to verify the experimental set-up. A wooden frame covered, front and back, with $5 \mathrm{~mm}$ clear acrylic sheets was used to hold the leaves to be tested. In order to confirm that only radio waves propagating directly through the wooden frame were received by the receiver (i.e. no multipath signals), a metal sheet, impenetrable to radio waves, was temporarily attached to the front of the frame. The position of the frame relative to the transceivers was then optimised such that the RSSI was below the minimum measurable power level for our equipment $(-80 \mathrm{dBm})$.

In order to measure a potential effect of the wooden frame itself, each of the empty frames was positioned between the transceivers and the RF signal loss, relative to no frame in place, was measured. Irrespective of frame size, the RF loss through the empty frame was confirmed to be below the measurement resolution of $0.1 \mathrm{~dB}$, which indicated that any loss associated with the frame of leaves would be solely due to the presence of the contained material inside.

\subsection{Measurements with Leaves}

A wooden frame (inner dimensions $600 \mathrm{~mm} \times 560 \mathrm{~mm} \times 42 \mathrm{~mm}$ ) was completely filled with freshly-plucked, turgid Eucalyptus laevopinea (silver top stringybark) leaves such that there was no visible gap between the frame and leaves when the frame is flipped over. The filled frame was then weighed. The RSSI $(\mathrm{dBm})$ for no obstruction between the transceivers was measured for 3 minutes and then the frame filled with leaves was placed on the stand and signal strength was again measured for 3 minutes. The difference between the time-average RSSI with and without frame in place was converted to a time-averaged RF loss associated with the leaves. The sequence of frame and no frame measurements was repeated three times to provide a measurement average. The RF loss $(L)$ associated with the sample of leaves was then calculated using,

$$
L(\mathrm{~dB})=\operatorname{RSSI}(\text { no frame })-\operatorname{RSSI}(\text { frame + leaves }) \text {. }
$$

Following the RSSI measurements with and without the frame in place, the leaves were removed from the frame and oven-dried in a vacuum oven at a temperature of $60^{\circ} \mathrm{C}$ and $80 \mathrm{kPa}(60 \mathrm{cmHg})$ vacuum gauge pressure for one hour. As condensation and the temperature of the transmitting material effects radio wave transmission, the hot leaves were then spread on a table surface to both cool down and allow residual water vapour to dissipate rather than condense. The frame was then refilled with the cooled leaves and weighed. The frame containing the now partially dried leaves was then placed on the stand at the experimental site and the process of measuring the RSSI was repeated.

The process of partial drying and remeasuring the RSSI was repeated until no further weight loss from drying was achieved (i.e. leaves were considered dry). At this point, the leaves are yellowish and brownish in colour and were brittle.

At this end point, the mass of the water $\left(m_{w}\right)$ in the freshly plucked and each partially-dried, leaf sample was retrospectively calculated from the known mass 
of the leaf samples and the final dry weight of the leaves.

The measurement sequence was repeated for frame thicknesses of $63 \mathrm{~mm}, 105$ $\mathrm{mm}, 147 \mathrm{~mm}$ and $195 \mathrm{~mm}$. The densities of the material before drying in each frame were in the range 0.33 to $0.39 \mathrm{~g} / \mathrm{cm}^{3}$.

\subsection{Calculation of Effective Water Path (EWP)}

The data from the hub's SD card was transferred to an Excel file for analysis. For each leaf sample, the difference between the weight of the frame filled with leaves and when empty yields the weight of the leaves in $\mathrm{kg}$. The weight of water inside the leaves in each of the leaf samples was then calculated by subtracting the weight of the dry leaves (final leaf state after successive partial drying steps) from the weight of leaves at different stages of drying.

The radio wave passes through vegetation depth, $d_{v}$ containing a distributed mass, $m_{w}$ of water $(\mathrm{kg})$. In order to quantify the equivalent amount of water affecting the radio wave, we define the effective water path (EWP) as the thickness of a sheet of $100 \%$ water with the same mass. If the dimension of the frame are $d_{r}, X$, and $y$ then the volume of the frame $V\left(\mathrm{~m}^{3}\right)$ is simply

$$
V=x \times y \times d_{v} .
$$

And the water mass is

$$
m_{w}=\rho_{w} \times \mathrm{EWP} \times x \times y,
$$

where, $\rho_{w}$ is the density of pure water $1000 \mathrm{~kg} / \mathrm{m}^{3}$. Hence,

$$
\mathrm{EWP}=\frac{m_{w} \times d_{v}}{\rho_{w} \times V} .
$$

The weight of water inside the leaves was converted to an effective water path (EWP), expressed now in mm, using Equation (5)

$$
\mathrm{EWP}=\left(\frac{m_{w} \times d_{v}}{\rho_{w} \times V}\right) \times 1000 .
$$

Note that both $\mathrm{m}_{\mathrm{w}}$ and EWP will be zero for dry leaves.

\section{Results and Discussion}

Figure 2 shows the RF loss through leaves for five different thicknesses of the frames ( $42 \mathrm{~mm}, 63 \mathrm{~mm}, 105 \mathrm{~mm}, 147 \mathrm{~mm}$ and $195 \mathrm{~mm}$ ) as functions of EWP. The maximum measured loss is $30 \mathrm{~dB}$ and any loss higher than this was not measurable with the experimental equipment. It was observed from the data that the RF loss did decrease with reduction of effective water path length associated with drying. The RF loss for completely dried leaves was lower than that for leaves partially dried to any extent for each frame thickness tested, but it was not zero. While most of the RF loss is associated with water in the leaves, there is still some residual $\mathrm{RF}$ loss when the leaves are completely dried.

It can be seen from Figure 2 that the RF loss is greater if the vegetation depth is greater, even if the total amount of water in the radio path is the same (and 
therefore the density of the contained water is less). Furthermore, when all the free water was removed by drying, the RF loss of the dried material was not zero and had an increasing trend with vegetation depth. These results are consistent with some RF loss being associated with the non-water part of the leaf material that is in addition to the generally greater loss due to water.

The result of a multiple regression model fit to the experimental data is

$$
\mathrm{EWP}=0.007 L^{2}+0.234 L-0.01 d_{v},
$$

$$
\left(r^{2}=0.92 \text {; Range }=0.0-14.3 \mathrm{~mm} \text {; S.E. } \pm 0.87 \mathrm{~mm} \text {, significant } \mathrm{p}<10^{-5}\right),
$$

where, EWP and $d_{v}$ are in $\mathrm{mm}$ and $L$ is in $\mathrm{dB}$. The same units apply for the models in Table 1. The RF loss $L$ linear term has the greatest predictive value. The nonlinear $L^{2}$ term and the vegetation depth $d_{v}$ term have a relatively small effect on the prediction. This is illustrated by Table 1 which compares the standard error of the predicted $E W P$ for some simpler regression equations.

The standard error of the predicted EWP by the full equation $(0.87 \mathrm{~mm})$ is moderately better than that for an equation containing only $L(1.26 \mathrm{~mm})$. Figure 3 shows the predicted EWP calculated from RF loss and vegetation depth using

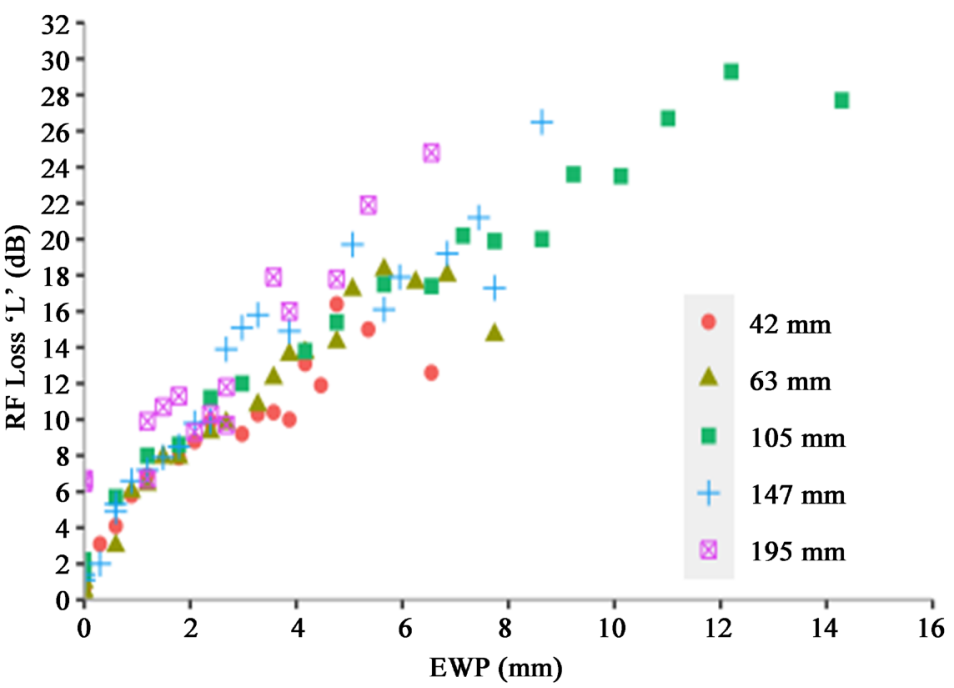

Figure 2. RF Loss $(\mathrm{dB})$ versus effective water path length $(\mathrm{mm})$ during drying of eucalyptus leaves, for five frame thicknesses. Legend shows the thickness of the frame (vegetation depth $d_{v}$ ). Data points corresponding to fresh leaves are generally toward the upper right with both the RF loss and EWP generally declining as drying progressed.

Table 1. Multiple regression models to predict $E W P$.

\begin{tabular}{ccccc}
\hline $\begin{array}{c}\text { Predictor } \\
\text { Variables }\end{array}$ & Model & $\boldsymbol{I}^{2}$ & SE $(\mathrm{mm})$ & \\
\hline Full Equation & $\mathrm{EWP}=0.007 L^{2}+0.234 L-0.01 d_{v}$ & 0.92 & \pm 0.87 & $\mathrm{p}<10^{-5}$ \\
$L$ and $d_{V}$ & $\mathrm{EWP}=0.423 L-0.011 d_{v}$ & 0.90 & \pm 0.97 & $\mathrm{p}<10^{-6}$ \\
$L$ and $L^{2}$ & $\mathrm{EWP}=0.008 L^{2}+0.203 L$ & 0.89 & \pm 1.02 & $\mathrm{p}<10^{-4}$ \\
Only $L$ & $\mathrm{EWP}=0.405 L-1.26$ & 0.87 & \pm 1.12 & $\mathrm{p}<10^{-6}$ \\
\hline
\end{tabular}




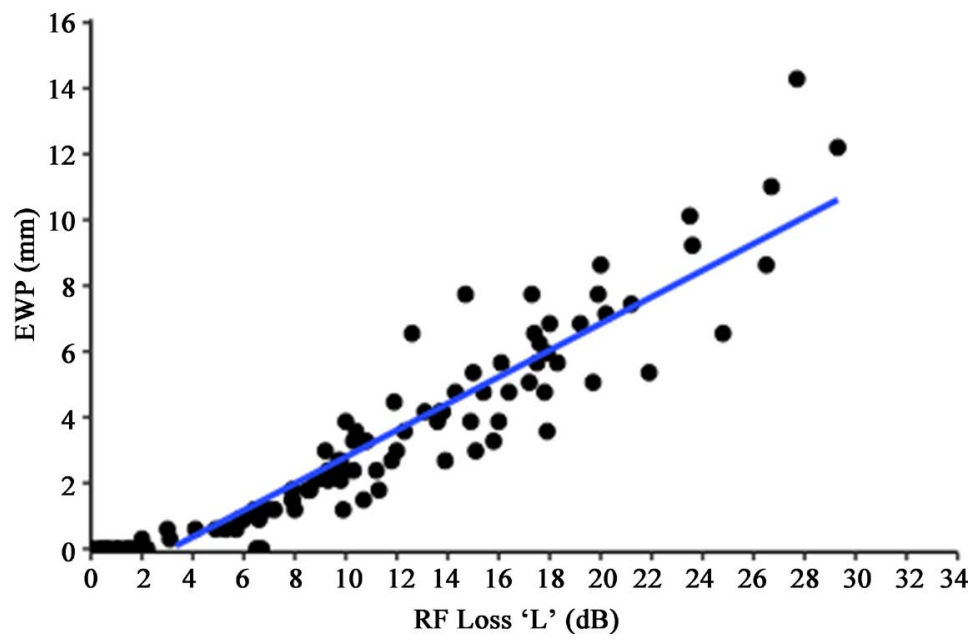

Figure 3. Predicted effective water path length (EWP) from Equation (6) compared to experimental values (circles) with all measurements pooled. Line shows prediction.

Equation (6) compared to the experimental EWP calculated from the change in weight of frame of leaves during drying.

RF loss through vegetation such as leaves and trees is strongly related to the amount of water in vegetation, which is consistent with the previous modelling by Le Vine and Karam [37] and studies conducted by Nakajima, et al. [38].

For our measurements at $2.4 \mathrm{GHz}$ frequency, there is a nonlinear relationship between EWP and radio loss in $\mathrm{dB}$. The dependence of RF loss on water content is through its permittivity. As RF loss changes non-linearly with permittivity, a nonlinear relationship seems plausible. This result can be compared to the previous modelling [37] in which the attenuation associated with a vegetation canopy is calculated using a discrete scatterer model. The nearest radio frequency to $2.4 \mathrm{GHz}$ (used in our experiments) in their results is $1 \mathrm{GHz}$. A comparison of the trends can be made but not the RF loss in absolute terms because it is strongly affected by frequency. They predicted that the attenuation varies almost linearly with moisture content of vegetation.

Other than moisture content inside the leaves and the vegetation depth, the density of packing of leaves inside the frame might be a factor causing the radio loss. This factor couldn't be verified with the experiment we carried out, but we hope that doing an experiment with a whole tree and comparing the results can verify whether density of packing of leaves (or distribution or orientation of the leaves in case of a tree) is a factor or not.

Since the transceivers used can measure RF loss up to $30 \mathrm{~dB}$, the results are only valid for EWP up to $14 \mathrm{~mm}$. This can be improved by using other transceivers which measures loss higher than $30 \mathrm{~dB}$.

We placed the frame of leaves close to the antenna in order to ensure that radio waves being measured did indeed travel through the leaves rather than some spurious path (via reflection from the ground, for example). This is in the near field of the antenna. Analysis of radio wave propagation is complicated in the antenna's near field and it would be preferable to place the material being tested 
further from it. To allow for the diverging radio beam, the size of the frame must be then increased and soon becomes impractical. For measurements on whole trees, however, this problem is resolved due to their greater size.

The result from this paper was further compared with our RF model through vegetation in Peden, Bradbury, Lamb and Hedley [42].

\section{Conclusion}

It can be concluded from the results above that there is a nonlinear relationship between radio loss in $\mathrm{dB}$ at $2.4 \mathrm{GHz}$ and effective water path (EWP) of Eucalyptus leaves. EWP is the dominant factor compared to vegetation depth. This work raises the possibility of estimating the water content of whole trees based on the radio loss and size of the tree. Further work is being carried out by us to predict the water content of a whole tree using RF loss.

\section{Funding}

This research did not receive any specific grant from funding agencies in the public, commercial, or not-for-profit sectors.

\section{Acknowledgements}

The first author (SP) acknowledges receipt of a Tuition Fee-Wavier Scholarship from the University of New England. DWL acknowledges the support of Food Agility CRC Ltd, funded under the Commonwealth Government CRC Program. The CRC Program supports industry-led collaborations between industry, researchers, and the community. All authors gratefully acknowledge the contribution of Derek Schneider and Patrick Littlefield from UNE for their help in setting up the experiment, and Prof. Jeremy Bruhl from UNE for helping us identify the eucalyptus species used for the experiment.

\section{Conflicts of Interest}

The authors declare no conflicts of interest regarding the publication of this paper.

\section{References}

[1] Allen, C.D., et al. (2010) A Global Overview of Drought and Heat-Induced Tree Mortality Reveals Emerging Climate Change Risks for Forests. Forest Ecology and Management, 259, 660-684. https://doi.org/10.1016/j.foreco.2009.09.001

[2] Boland, D.J., et al. (2006) Forest Trees of Australia. 5th Edition, Victoria CSIRO Publishing, Victoria.

[3] Matusick, G., Ruthrof, K., Brouwers, N., Dell, B. and Hardy, G. (2013) Sudden Forest Canopy Collapse Corresponding with Extreme Drought and Heat in a Mediterranean-Type Eucalypt Forest in Southwestern Australia. European Journal of Forest Research, 132, 497-510. https://doi.org/10.1007/s10342-013-0690-5

[4] ABARES (2018) Australia's State of the Forests Report. Department of Agriculture and Water Resources, Australian. 
[5] Belyazid, S. and Giuliana, Z. (2019) Water Limitation Can Negate the Effect of Higher Temperatures on Forest Carbon Sequestration. European Journal of Forest Research, 138, 287-297. https://doi.org/10.1007/s10342-019-01168-4

[6] Kirkham, M.B. (2016) Elevated Carbon Dioxide: Impacts on Soil and Plant Water Relations. CRC Press, Boca Raton.

[7] Osakabe, Y., Osakabe, K., Shinozaki, K. and Tran, L.S. (2014) Response of Plants to Water Stress. Frontiers in Plant Science, 5, 86. https://doi.org/10.3389/fpls.2014.00086

[8] Pereira, J. and Pallardy, S. (1989) Water Stress Limitations to Tree Productivity. In: Biomass Production by Fast-Growing Trees, Springer, Berlin, 37-56. https://doi.org/10.1007/978-94-009-2348-5_3

[9] Pallardy, S., Pereira, J. and Parker, W. (1991) Measuring the State of Water in Tree Systems. In: Lassoie, J.P. and Hinckley, T.M., Eds., Techniques and Approaches in Forest Tree Ecophysiology, CRC Press, Boca Raton, 28-76.

[10] Zhou, J., Zhou, J., Ye, H., Ali, M.L., Nguyen, H.T. and Chen, P. (2020) Classification of Soybean Leaf Wilting Due to Drought Stress Using UAV-Based Imagery. Computers and Electronics in Agriculture, 175, Article ID: 105576.

[11] Resh, H.M. (2015) Signs of Plant Nutritional and Physiological Disorders and Their Remedies. In: Hydroponics for the Home Grower, CRC Press, Boca Raton, 76-89. https://doi.org/10.1201/b18069-16

[12] Peñuelas, J., Filella, I., Biel, C., Serrano, L. and Save, R. (1993) The Reflectance at the 950-970 nm Region as an Indicator of Plant Water Status. International Journal of Remote Sensing, 14, 1887-1905. https://doi.org/10.1080/01431169308954010

[13] Peñuelas, J., Filella, I., Serrano, L. and Save, R. (1996) Cell Wall Elasticity and Water Index (R970 nm/R900 nm) in Wheat under Different Nitrogen Availabilities. International Journal of Remote Sensing, 17, 373-382.

https://doi.org/10.1080/01431169608949012

[14] Datt, B. (1999) Remote Sensing of Water Content in Eucalyptus Leaves. Australian Journal of Botany, 47, 909-923. https://doi.org/10.1071/BT98042

[15] Balachander, D., Rao, T.R. and Mahesh, G. (2013) RF Propagation Experiments in Agricultural Fields and Gardens for Wireless Sensor Communications. Progress in Electromagnetics Research C, 39, 103-118. https://doi.org/10.2528/PIERC13030710

[16] Weissberger, M.A. (1982) An Initial Critical Summary of Models for Predicting the Attenuation of Radio Waves by Trees.

[17] Seville, A. and Craig, K. (1995) Semi-Empirical Model for Millimetre-Wave Vegetation Attenuation Rates. Electronics Letters, 31, 1507-1508. https://doi.org/10.1049/el:19951000

[18] Al-Nuaimi, M.O. and Stephens, R.B.L. (1998) Measurements and Prediction Model Optimisation for Signal Attenuation in Vegetation Media at Centimetre Wave Frequencies. IEE Proceedings-Microwaves, Antennas and Propagation, 145, 201-206. https://doi.org/10.1049/ip-map:19981883

[19] Adegoke, A.S. (2014) Measurement of Propagation Loss in Trees at SHF Frequencies. Ph.D. Thesis, Department of Engineering, University of Leicester, Leicester.

[20] Rogers, N.C., Seville, A., Richter, J., Ndzi, D., Savage, N., Caldeirinha, R., Shukla, A., Al-Nuaimi, M., Craig, K. and Vilar, E. (2002) A Generic Model of 1-60 GHz Radio Propagation through Vegetation. Final Report, Radio Agency, London.

[21] Rappaport, T.S. (1996) Wireless Communications: Principles and Practice. Prentice Hall, Hoboken. 
[22] Hristos, T.A., Stavros, V., Theodoros, F., Christian, R., Loukas, P., Manuela, Z. and Jana, K. (2014) A Computational Model for Path Loss in Wireless Sensor Networks in Orchard Environments. Sensors, 14, 5118-5135.

https://doi.org/10.3390/s140305118

[23] LaGrone, A.H. (1960) Forecasting Television Service Fields. Proceedings of the IRE, 48, 1009-1015. https://doi.org/10.1109/JRPROC.1960.287501

[24] Seville, A., Charriere, P.G.V., Powell, N. and Craig, K.H. (1995) Building Scatter and Vegetation Attenuation Measurements at $38 \mathrm{GHz}$. 9 th International Conference on Antennas and Propagation (ICAP), Eindhoven, April 1995, 46-50. https://doi.org/10.1049/cp:19950380

[25] Adegoke, A.S. and Siddle, D. (2015) Geometry Dependence of Vegetation Attenuation on Isolated Single Trees. European Journal of Engineering and Technology, 3, 36-42.

[26] Azevedo, J.A.R. and Santos, F.E.S. (2011) An Empirical Propagation Model for Forest Environments at Tree Trunk Level (Technical Report). IEEE Transactions on Antennas and Propagation, 59, 2357. https://doi.org/10.1109/TAP.2011.2143664

[27] Azevedo, J.A.R. and Santos, F.E.S. (2017) A Model to Estimate the Path Loss in Areas with Foliage of Trees. AEUE-International Journal of Electronics and Communications, 71, 157. https://doi.org/10.1016/j.aeue.2016.10.018

[28] Andrade-Sanchez, P., Pierce, F.J. and Elliott, T.V. (2007) Performance Assessment of Wireless Sensor Networks in Agricultural Settings. ASABE Paper, 073076. https://doi.org/10.13031/2013.23185

[29] Guo, X.-M. and Zhao, C. (2014) Propagation Model for 2.4 GHz Wireless Sensor Network in Four-Year-Old Young Apple Orchard. International Journal of Agricultural and Biological Engineering, 7, 47-53.

[30] Al-Nuaimi, M.O. and Hammoudeh, A.M. (1993) Attenuation Functions of Microwave Signals Propagated through Trees. Electronics Letters, 29, 1307-1308. https://doi.org/10.1049/el:19930872

[31] Adamy, D. (2015) Radio Propagation: Losses from Trees and Urban Areas. Journal of Electronic Defense, 38, 43.

[32] Benzair, B. (1993) Characterisation of Radio Wave Propagation inside Building and through Vegetation. University of Bradford, Bradford.

[33] Caldeirinha, R.F.S. (2001) Radio Characterisation of Single Trees at Micro and Millimetre Wave Frequencies. University of Glamorgan, Wales.

[34] Yang, X., Guo, X., Li, M., Sun, C., Hao, L., Qu, L. and Wang, Y. (2013) An Empirical Model for $2.4 \mathrm{GHz}$ Radio propagation in a Gala Apple Orchard and Evaluation of the Model Performance by Simulation. Transactions of the ASABE, 56, 15991611 .

[35] Perras, S. and Bouchard, L. (2002) Fading Characteristics of RF Signals Due to Foliage in Frequency Bands from 2 to $60 \mathrm{GHz}$. Proceedings of the 5 th International Symposium on Wireless Personal Multimedia Communications, 1, 267-271. https://doi.org/10.1109/WPMC.2002.1088174

[36] Muhammad, N.A., Rahman, T.A., Rahim, S.K.A., Kesavan, U. and Assis, M.S. (2013) Investigation of Wind and Rain Effects in a Foliated Tropical Region for Fixed Wireless Access. International Journal of Electronics, 101, 1314-1324. https://doi.org/10.1080/00207217.2013.853259

[37] Le Vine, D.M. and Karam, M.A. (1996) Dependence of Attenuation in a Vegetation Canopy on Frequency and Plant Water Content. IEEE Transactions on Geoscience and Remote Sensing, 34, 1090-1096. https://doi.org/10.1109/36.536525 
[38] Nakajima, I., Ohyama, F., Juzoji, H. and Ta, M. (2019) Developing a Scanner for Assessing Foliage Moisture. Journal of Multimedia Information System, 6, 155-164. https://doi.org/10.33851/JMIS.2019.6.3.155

[39] Schubert, F.M., Fleury, B.H. and Prieto-Cerdeira, R. (2009) Propagation Model for Wave Scattering Effects Caused by Trees. Proceedings COST Action IC0802 2nd Management Committee Meeting, Toulouse, France, 4-6 November.

[40] Caldeirinha, R.F.S., Morgadinho, S., Frazão, L., Cuiñas, I., Sanchéz, M. and AlNuaimi, M. (2006) Wind Incidence Effects on Channel Dynamics in Vegetation Media at $40 \mathrm{GHz}$. IEEE International Symposium on Geoscience and Remote Sensing, Denver, 31 July-4 August 2006, 1032-1035.

https://doi.org/10.1109/IGARSS.2006.266

[41] Salameh, H.A.S.M. (2019) Predicting Leaf State Effects on Radiowaves Based on Propagation Loss Measurements. MATEC Web of Conferences, 292, Article No. 02005. https://doi.org/10.1051/matecconf/201929202005

[42] Peden, S., Bradbury, R.C., Lamb, D.W. and Hedley, M. (2021) A Model for RF Loss through Vegetation with Varying Water Content. Journal of Electromagnetic Analysis and Applications, 13, 41-56. 